\title{
PRODUTIVIDADE E QUALIDADE NUTRICIONAL DE CULTIVARES DE FEIJÃO EM DIFERENTES ADUBAÇÕES ${ }^{1}$
}

\author{
Nutritional quality and yield of bean cultivars under different fertilization levels
}

\author{
Carlos Alberto de Bastos Andrade 2 , Sandra Magda Sanches Patroni ${ }^{3}$, \\ Edmar Clemente ${ }^{4}$, Carlos Alberto Scapim ${ }^{2}$
}

\begin{abstract}
RESUMO
O fornecimento adequado e equilibrado de nutrientes para o feijoeiro (Phaseolus vulgaris L.) por meio da calagem e adubação pode contribuir para o aumento da produtividade e o valor nutricional dos grãos. Portanto, avaliou-se o efeito da adubação na produtividade, componentes da produção, nos teores de macro e micronutrientes, proteína e triptofano nos grãos de três cultivares de feijão (Aporé, Pérola e Rudá). O delineamento experimental foi o de blocos casualizados, com quatro repetições, em esquema de parcela subdividida, sendo locados nas parcelas as diferentes adubações $\left(\mathrm{N}_{1}\right.$ - não adubado; $\mathrm{N}_{2}$ - adubação para produtividade esperada de até $1.200 \mathrm{~kg} \mathrm{ha}^{-1}, \mathrm{~N}_{3}$ - adubação para produtividade esperada acima de $2.500 \mathrm{~kg}^{-1}$ ). As subparcelas constaram das três cultivares. As adubações utilizadas foram suficientes para alcançar os níveis de produtividade esperados. A cultivar Rudá destacou-se das demais, com os maiores teores de Mg, S, Zn, Fe, Cu, Mn e B. A cultivar Aporé apresentou os maiores teores de K, N, proteína e triptofano. A cultivar Pérola obteve os maiores teores de Ca e P. A recomendação de adubação para atingir produtividade superior a $2.500 \mathrm{~kg} \mathrm{ha}^{-1}$ de grãos proporcionou as maiores produtividades, os maiores teores de $\mathrm{K}$, $\mathrm{N}$, $\mathrm{Fe}, \mathrm{Cu}, \mathrm{Mn}, \mathrm{B}$, proteína e triptofano nos grãos de feijão.
\end{abstract}

Termos para indexação: Teores de nutrientes, proteína, triptofano, Phaseolus vulgaris L.

\begin{abstract}
The appropriate and balanced supply of nutrients of the bean plant (Phaseolus vulgaris L.) achieved by liming and fertilization can contribute towards increasing the grain yield and nutritional value. It was evaluated the effect of the levels of fertilization on the productivity, components of the production, composition of macro and micronutrients, protein and tryptophan in the grains of three bean cultivars (Aporé, Pérola and Rudá). The experimental design was composed of random blocks, with four replicates, in split-plot design, considering the different levels of fertilization $\left(\mathrm{N}_{1}\right.$ - no fertilized; $\mathrm{N}_{2}-$ fertilization level for an expected grain yield of $1,200 \mathrm{~kg} \mathrm{ha}^{-1}, \mathrm{~N}_{3}$ - fertilization for expected grain yield above 2,500 kg ha-1). The split-plot random blocks design consisted of the three cultivars. The fertilizers used were adequate to reach the expected levels of productivity. The higher productivity was obtained when all cultivars were fertilized $\mathrm{N}_{3}$. Rudá cultivar showed the largest levels of Mg, S, Zn, Fe, $\mathrm{Cu}, \mathrm{Mn}$ and B. Aporé cultivar presented the largest levels of $\mathrm{K}, \mathrm{N}$, protein and tryptophan, while the cultivar Pérola showed the largest levels of $\mathrm{Ca}$ and $\mathrm{P}$. The fertilizing recommendation to obtain productivity superior to 2,500 $\mathrm{kg} \mathrm{ha}^{-1}$, produced the largest levels of $\mathrm{K}, \mathrm{N}, \mathrm{Fe}, \mathrm{Cu}, \mathrm{Mn}, \mathrm{B}$, protein and tryptophan in the bean grains.
\end{abstract}

Index terms: Nutrients contents, protein, tryptophan, Phaseolus vulgaris.

(Recebido para publicação em 30 de janeiro de 2004 e aprovado em 26 de agosto de 2004)

\section{INTRODUÇÃO}

O Brasil é um dos maiores produtores e o maior consumidor mundial de feijão comum (Phaseolus vulgaris L.), produzindo nos anos de 2002 e 2003, aproximadamente, 3,0 milhões de toneladas ano ${ }^{-1}$, em uma área cultivada de 4,2 milhões de hectares, o que implica uma produtividade média de $714 \mathrm{~kg} \mathrm{ha}^{-1}$ (CONAB, 2003), considerada baixa, uma vez que em monocultivo com alta tecnologia tem-se obtido, em experimentos, mais de $4.000 \mathrm{~kg} \mathrm{ha}^{-1}$ (VIEIRA et al., 1999).
$\mathrm{O}$ fornecimento adequado e equilibrado de nutrientes para o feijoeiro, pelo uso de adubos minerais, poderá contribuir não só para aumentar a produtividade, mas também para melhorar o valor nutricional do feijão (TEIXEIRA, 2000). Assim, o uso da calagem e da adubação equilibrada poderá fornecer nutrientes que não se encontram em quantidades suficientes no solo, promovendo maior produtividade e melhor qualidade organoléptica e nutricional.

A qualidade do produto agrícola, de acordo com Malavolta (1981), pode ser definida como sendo o con-

1. Trabalho realizado com auxílio financeiro do CNPq.

2. Engenheiro Agrônomo, Doutor, Professor do Departamento de Agronomia da UEM. Av. Colombo, 5790. 87020-900. Maringá, PR. cabandrade@uem.br.

3. Aluna do Programa de Pós-graduação em Agronomia - Produção Vegetal da UEM.

4. Químico, PhD., Professor do Departamento de Química da UEM. 
junto de características que aumenta o seu valor nutritivo para o homem ou animal ou que acentua suas propriedades organolépticas, ou aumenta o seu valor comercial ou industrial, ou resistência ao transporte e armazenamento. Assim, é possível que por meio da adubação possa, além de aumentar a produtividade, melhorar o valor nutricional do feijoeiro.

Em relação aos nutrientes minerais, os grãos de feijão são ricos, principalmente em potássio (25-30\% do conteúdo total de minerais), fósforo (cerca de $0,4 \%$ ), ferro (cerca de $0,007 \%$ ) cálcio, zinco e magnésio (ARAÚJO, 1996). Essa planta apresenta conteúdo relativamente elevado de proteína, em média entre 22\% e 26\% (BARAMPAMA e SIMARD, 1993), e as principais frações solúveis (globulinas e albuminas) representam em torno de $75 \%$ do total.

Em estudo realizado por Sgarbieri e Whitaker (1982) com 25 variedades de feijão oriundos da América Central, verificou-se que a metionina e o triptofano estavam em baixas concentrações nos grãos de todas as variedades. O teor de metionina variou entre 0,80 e 1,39 g/100 g de proteína e o de triptofano, entre 0,56 e $0,94 \%$. O teor de lisina estava entre 7,22 e 9,22\%. A concentração de proteína total nos grãos dessas variedades oscilou de 20,1 a 27,9\%.

Observando-se os teores de elementos minerais encontrados nas diferentes partes do feijoeiro, de maneira geral, a exigência nutricional do feijoeiro em ordem decrescente é a seguinte: N, K, Ca, Mg, S, P, Fe, $\mathrm{Mn}, \mathrm{B}, \mathrm{Zn}$ e $\mathrm{Cu}$ e a exportação pelos grãos, da mesma maneira: N, K, P, S, Ca, Mg, Fe, Zn, $\mathrm{Mn}, \mathrm{B}$ e $\mathrm{Cu}$. Em $1 \mathrm{t}$ de grãos, a exportação média de nutrientes (em $\mathrm{kg} \mathrm{ha}^{-1}$ ) corresponde a 35,5 de $\mathrm{N}$; 4,0 de P; 15,3 de K; 3,1 de Ca; 2,6 de Mg e 5,4 de $\mathrm{S}$. Para os micronutrientes, a exigência nutricional do feijoeiro em ordem decrescente é a seguinte: $\mathrm{Zn}, \mathrm{Cu}$, B e Mn (ANDRADE, 1997).

A despeito da grande inter-relação existente entre adubação e qualidade nutricional de grãos, poucos trabalhos são encontrados na literatura. Estudos nesse sentido, principalmente envolvendo cultivares em uso pelos produtores, são altamente desejáveis e necessários. Portanto, conduziu-se este trabalho com o objetivo de avaliar o efeito da adubação no rendimento e na qualidade nutricional das cultivares de feijão Aporé, Pérola e Rudá.

\section{MATERIAL E MÉTODOS}

O trabalho foi conduzido em campo no período de novembro/2001 a fevereiro/2002, em um Nitossolo (EMBRAPA, 1999) da área experimental da Universi- dade Estadual de Maringá (UEM), Maringá-PR. O delineamento experimental adotado foi o de blocos inteiramente casualizados com quatro repetições, em esquema de parcelas subdivididas, locando-se às parcelas três níveis de adubação ( $\mathrm{N}_{1}$ - não adubado; $\mathrm{N}_{2}$ - adubação para produtividade esperada de até $1.200 \mathrm{~kg} \mathrm{ha}^{-1} \mathrm{e} \mathrm{N}_{3}$ - adubação para produtividade esperada acima de $2.500 \mathrm{~kg}$ $h^{-1}$ ) e, às subparcelas, três cultivares (Aporé, Pérola e Rudá).

Os resultados da análise química do solo foram realizadas no Laboratório de Solos e Tecido Vegetal do Departamento de Agronomia da UEM, tendo o solo coletado antes da adubação de plantio apresentando o seguinte: $\mathrm{pH}\left(\mathrm{CaCl}_{2}\right)$ : 5,3 (Alto); $\mathrm{pH}\left(1: 2,5-\mathrm{H}_{2} \mathrm{O}\right)$ : 6,0 (Alto); P (Mehlich l): $15 \mathrm{mg} / \mathrm{dm}^{3}$ (Bom); K (Mehlich l): 0,70 cmolc $\mathrm{dm}^{-3}$ (Muito alto); Ca: 7,39 cmolc $\mathrm{dm}^{-3}$ (Muito bom); Mg: 2,18 cmolc $\mathrm{dm}^{-3}$ (Muito bom); Al:

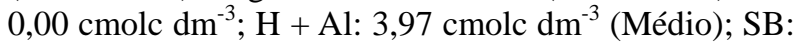
10,28 cmolc $\mathrm{dm}^{-3}$ (Muito bom); T: 14,25 cmolc $\mathrm{dm}^{-3}$ (Bom); V \%: 72 (Bom); Fe: 69,17 mg.dm ${ }^{-3}$ (Alto); Zn: 10,0 mg.dm ${ }^{-3}$ (Alto); Cu: 25,57 mg.dm ${ }^{-3}$ (Alto); Mn: 326,01 mg.dm ${ }^{-3}$ (Alto); C: 9,58 g/dm ${ }^{-3}$ (Muito bom). A interpretação dos resultados foi feita de acordo com a CFSEMG (1999). De acordo com essa Comissão, verifica-se que não houve necessidade de se efetuar a calagem, independentemente do método adotado.

Os níveis de adubação $\mathrm{N}_{2}$ e $\mathrm{N}_{3}$ foram definidos, após análise química do solo, com base nas Recomendações para o Uso de Corretivos e Fertilizantes em Minas Gerais - $5^{\mathrm{a}}$ Aproximação (CFSEMG, 1999): níveis de produtividade 1 (até $1.200 \mathrm{~kg} \mathrm{ha}^{-1}-\mathrm{N}_{2}$ ) e 4 (acima de $2.500 \mathrm{~kg} \mathrm{ha}^{-1}-\mathrm{N}_{3}$ ). Por conseguinte, a adubação $\mathrm{N}_{2}$ constou ( $\mathrm{kg} \mathrm{ha}^{-1}$ ) de 20, 30 e 20, respectivamente, de $\mathrm{N}, \mathrm{P}_{2} \mathrm{O}_{5}$ e $\mathrm{K}_{2} \mathrm{O}$ no plantio, e $20 \mathrm{~kg}$ de $\mathrm{N}$ em cobertura e a $\mathrm{N}_{3}$ de 40 , 70 e 20 respectivamente, de $\mathrm{N}, \mathrm{P}_{2} \mathrm{O}_{5}$ e $\mathrm{K}_{2} \mathrm{O}$ no plantio, e $60 \mathrm{~kg}$ de $\mathrm{N}$ em cobertura, aos 20 e 30 dias após a emergência. As fontes de $\mathrm{N}$, P e K foram uréia, superfosfato simples e cloreto de potássio, respectivamente.

As subparcelas foram constituídas de cinco linhas de feijão de cinco metros de comprimento, espaçadas de 0,50 m entre si. Foram consideradas úteis as três fileiras centrais, excluindo-se $0,50 \mathrm{~m}$ da cabeceira $(6,0$ $\mathrm{m}^{2}$ ). O preparo do solo constou de uma aração e uma gradagem. A semeadura foi realizada de forma manual. A densidade de semeadura foi de 15 sementes viáveis por metro linear, em todos os tratamentos.

Avaliaram-se o rendimento de grãos e os seus componentes primários. Os componentes do rendimento foram determinados na amostra aleatória de 10 plantas coletadas na área útil de cada subparcela. A 
determinação do número médio de vagens por planta foi realizada pela contagem do total de vagens das 10 plantas, determinando-se, a seguir, o número médio de grãos por vagem pela contagem do total de grãos. A massa de 100 grãos foi obtida da pesagem de amostra aleatória.

Determinou-se o rendimento de grãos pela pesagem dos grãos obtidos na área útil da subparcela. O peso obtido foi expresso em $\mathrm{kg} \mathrm{ha}^{-1}$ (corrigido para $13 \%$ de umidade). As amostras dos grãos secos e moídos foram submetidas à digestão nitroperclórica (JOHNSON e URICH, 1959), em triplicata, para as análises de P, K, $\mathrm{Ca}, \mathrm{Mg}, \mathrm{S}, \mathrm{Fe}, \mathrm{Cu}, \mathrm{Zn}$ e $\mathrm{Mn}$. O teor de $\mathrm{P}$ foi determinado pelo método da colorimetria do azul de molibdênio (MALAVOLTA et al., 1997); o de S, por adição de sulfato de bário; e os teores de Ca, Mg, Fe, Mn, Zn, K e Cu foram determinados por espectrofotometria de absorção atômica, segundo AOAC (1975). O B foi extraído por digestão seca e determinado com colorimetria da azometina H (MALAVOLTA et al., 1997). O N total foi determinado por digestão com ácido sulfúrico mais sais e catalisadores, utilizando o método semimicro Kjeldahl (MALAVOLTA et al., 1997); sendo a proteína bruta calculada pelo fator de conversão 6,25, normalmente usado para transformar o $\mathrm{N}$ total em nitrogênio (\%) e daí em proteína (\%). Determinou-se o triptofano pelo método de Opienska-Blouth et al. (1963), modificado por Clemente e Portela (1987).

Os dados foram submetidos à análise de variância, sendo os efeitos dos níveis de adubação e de cultivares avaliados por meio do teste Duncan, de acordo com Campos (1984).

\section{RESULTADOS E DISCUSSÃO}

A análise de variância relativa ao número de vagens por planta e de grãos por vagem, produtividade e massa de 100 grãos revelou que a adubação influenciou significativamente $(\mathrm{P}<0,05)$ essas variáveis, sem, contudo, haver interação (Tabela 1).

A adubação com 40-70-20 kg ha ${ }^{-1}$ de $\mathrm{N}, \mathrm{P}_{2} \mathrm{O}_{5}$ e $\mathrm{K}_{2} \mathrm{O}$ no plantio mais $60 \mathrm{~kg} \mathrm{ha}^{-1}$ de $\mathrm{N}$ em cobertura $\left(\mathrm{N}_{3}\right)$ proporcionou o maior número de vagens por planta (Tabela 1). A adubação $\mathrm{N}_{2}$ não aumentou significativamente o número de vagens por planta, quando compara- do com o não adubado $\left(\mathrm{N}_{1}\right)$, pois a fertilidade natural do solo é boa. O que deve ter influenciado no maior número de vagens por planta na adubação $\mathrm{N}_{3}$ foi a maior dose de $\mathrm{P}_{2} \mathrm{O}_{5}$ e $\mathrm{N}$, uma vez que o feijoeiro responde bem a esses nutrientes (ANDRADE, 1997). As cultivares Rudá e Aporé apresentaram o maior número de vagens por planta, provavelmente devido à maior absorção e utilização de nutrientes, principalmente de P e N, o que não refletiu na produtividade.

$\mathrm{O}$ tratamento $\mathrm{N}_{3}$ apresentou maior massa de 100 sementes (27,51 g), inferindo-se que a adubação foi eficiente em aumentar o tamanho do grão. Esse fato está de acordo com dados obtidos por Guerra et al. (2000), os quais, ao aumentarem a dose de $\mathrm{N}$ na adubação, obtiveram aumento na massa de 100 grãos, embora esse aumento tenha dependido da disponibilidade hídrica para a cultura. Houve ainda diferenças significativas entre as cultivares, tendo a Pérola apresentado maior massa (26,65g).

Nota-se que apesar das diferenças entre as cultivares quanto ao número de vagens por planta (Pérola menor que Rudá e Aporé), os rendimentos de grãos não diferiram entre as cultivares. Isso foi decorrente da maior massa de 100 grãos da cultivar Pérola, o que teria causado certa compensação, aumentando a produtividade. Essa capacidade de compensação entre componentes do rendimento, também chamada de plasticidade da cultura, foi constatada por Fernandes (1987).

É possível verificar pela Tabela 1 que o tratamento $\mathrm{N}_{3}\left(100 \mathrm{~kg} \mathrm{ha}^{-1}\right.$ de $\mathrm{N}$ ) proporcionou maior produtividade do que os tratamentos $\mathrm{N}_{1}(\mathrm{sem} \mathrm{N})$ e $\mathrm{N}_{2}(40 \mathrm{~kg}$ $\mathrm{ha}^{-1}$ de N). Como nesse tratamento também foi aplicada no solo a maior quantidade de fósforo $\left(70 \mathrm{~kg} \mathrm{ha}^{-1}\right.$ de $\mathrm{P}_{2} \mathrm{O}_{5}$ ), é possível que esses efeitos devam-se também ao $\mathrm{P}$ e não somente ao incremento de N. Para o feijoeiro, é muito importante que o nutriente seja colocado à disposição da planta em tempo, local e quantidade adequados, pois a espécie é considerada exigente em nutrientes, pelo fato de o sistema radicular ser pequeno e pouco profundo e de ciclo curto (ROSOLEM e MARUBAYASHI, 1994). Segundo Arf (1999), entre os nutrientes absorvidos, o nitrogênio é exportado em maiores quantidades; além disso, é o elemento que, juntamente com o fósforo, tem proporcionado as maiores respostas em produção. 
ANDRADE, C. A. de B. et al.

TABELA 1 - Número de vagens por planta, massa de 100 sementes (g), produtividade (kg ha ${ }^{-1}$ ), número de sementes por vagem, nos tratamentos sem e com adubação $\left(\mathrm{N}_{1}, \mathrm{~N}_{2}, \mathrm{~N}_{3}\right)$. UEM, Maringá-PR, 2001.

\begin{tabular}{|c|c|c|c|c|}
\hline Nível de adubação & Pérola & Rudá & Aporé & Média \\
\hline \multicolumn{5}{|c|}{ Número de vagens por planta } \\
\hline N1 & 5,3 & 13,4 & 9,4 & $9,4 b$ \\
\hline N2 & 11,2 & 11,1 & 11,0 & $11,1 b$ \\
\hline N3 & 13,7 & 18,4 & 19,6 & $17,2 \mathrm{a}$ \\
\hline Média & $10,1 \mathrm{~B}$ & $14,3 \mathrm{~A}$ & $13,3 \mathrm{~A}$ & \\
\hline \multicolumn{5}{|c|}{ Massa de 100 sementes (g) } \\
\hline N1 & 25,01 & 18,74 & 22,72 & $22,15 \mathrm{c}$ \\
\hline N2 & 25,20 & 20,03 & 23,75 & $23,00 \mathrm{~b}$ \\
\hline N3 & 29,74 & 24,02 & 28,78 & $27,51 \mathrm{a}$ \\
\hline Média & 26,65 A & $20,93 \mathrm{C}$ & $25,08 \mathrm{~B}$ & \\
\hline \multicolumn{5}{|c|}{ Produtividade (kg ha ${ }^{-1}$ ) } \\
\hline N1 & 1.277 & 1.277 & 1.086 & $1.197 \mathrm{~b}$ \\
\hline N2 & 1.300 & 1.368 & 1.167 & $1.278 \mathrm{~b}$ \\
\hline N3 & 2.748 & 3.072 & 2.576 & 2.799a \\
\hline Média & 1.775 & 1.889 & 1.610 & \\
\hline \multicolumn{5}{|c|}{ Número de sementes por vagem } \\
\hline N1 & 6,0 & 5,3 & 5,1 & 5,5 a \\
\hline N2 & 5,5 & 5,6 & 5,9 & 5,6 a \\
\hline N3 & 5,9 & 6,1 & 5,2 & $5,7 \mathrm{a}$ \\
\hline Média & 5,8 & 5,7 & 5,4 & \\
\hline
\end{tabular}

Letras maiúsculas iguais na linha e letras minúsculas iguais na coluna indicam que as médias não diferem entre si, pelo teste Duncan $(P>0,05)$.

$\mathrm{N}_{1}=$ Sem adubação; $\mathrm{N}_{2}=20-30-20 \mathrm{~kg} \mathrm{ha}^{-1}$ de $\mathrm{N}, \mathbf{P}_{2} \mathrm{O}_{5}$ e $\mathrm{K}_{2} \mathrm{O}$, respectivamente, no plantio, mais $20 \mathrm{~kg}$ de $\mathrm{N}$ ha 1 em cobertura; e $N_{3}=40-70-20 \mathrm{~kg} \mathrm{ha}^{-1}$ de $\mathrm{N}, \mathrm{P}_{2} \mathrm{O}_{5}$ e $\mathrm{K}_{2} \mathrm{O}$, respectivamente, no plantio mais $60 \mathrm{~kg} \mathrm{de} \mathrm{N}$ ha $^{-1}$ em cobertura.

A análise de variância dos teores de macro e micronutrientes, proteína e triptofano nos grãos de feijão revelou que a adubação influenciou significativamente $(\mathrm{P}<0,05)$ os teores de $\mathrm{N}, \mathrm{Cu}, \mathrm{Mn}$, proteína e triptofano. As cultivares diferiram significativamente quanto aos teores de N, P, K, Ca, S, B, Fe, Mn, proteína e triptofano, mas a interação adubação $\mathrm{x}$ cultivar não se mostrou significativa $(\mathrm{P}>0,05)$ em relação a nenhuma das variáveis (Tabelas 2, 3 e 4).

A extração de nutrientes pelos grãos seguiu a ordem $\mathrm{N}>\mathrm{S}>\mathrm{K}>\mathrm{Mg}>\mathrm{Ca}>\mathrm{P}$. Apenas o teor de $\mathrm{N}$ aumentou com a adubação (Tabela 2). As cultivares Aporé e Pérola apresentaram teores de $\mathrm{N}$ de 4,09 e 3,96\%, respectivamente. A cultivar Rudá apresentou menor teor de $\mathrm{N}$ 
(3,75\%), diferindo da cultivar Aporé. Pelos resultados obtidos para a média das cultivares, verifica-se que a adubação do tratamento $\mathrm{N}_{3}$ proporcionou maior teor de N (4,31\%) e, sem adubação, obteve-se o menor teor (3,55\%). Na adubação do tratamento $\mathrm{N}_{2}$, o teor de $\mathrm{N}$ foi de $3,95 \%$, superando, significativamente, o teor de $\mathrm{N}$ sem adubação. Nos tratamentos $\mathrm{N}_{2}\left(20+20 \mathrm{~kg}\right.$ de N/ha $\left.{ }^{-1}\right)$ e $\mathrm{N}_{3}\left(40+60 \mathrm{~kg}\right.$ de $\left.\mathrm{N} / \mathrm{ha}^{-1}\right)$, o teor de $\mathrm{N}$ elevou-se proporcionalmente.

Os maiores teores de $\mathrm{P}$ foram alcançados com as cultivares Pérola e Aporé, que diferiram significativamente da cultivar Rudá. A adubação não influenciou significativamente os teores de P, (Tabela 2), o que equivale a dizer que o incremento de 30 ou $70 \mathrm{~kg} \mathrm{ha}^{-1}$ de $\mathrm{P}_{2} \mathrm{O}_{5}$ no plantio não foi suficiente para alterar o teor de macronutrientes no grão. Relatos sobre a exigência metabólica de $\mathrm{P}$ de cada espécie ou cultivar são descritos por Fernandes (1998). Esses autores mostram que a absorção do P da solução do solo está relacionada com a relação da energia de ligação de $\mathrm{P}$ e com a capacidade tampão desse elemento no solo, ou seja, em solos com maior capacidade tampão, há uma menor extração de $\mathrm{P}$ pelas plantas. Eles mostram ainda que a concentração de $\mathrm{P}$ na solução do solo próxima às raízes, que é função dos mecanismos que determinam a disponibilidade de $\mathrm{P}$ no solo, é capaz de influenciar diretamente a absorção de $\mathrm{P}$ e seu acúmulo na parte aérea.

As cultivares Aporé e Pérola apresentaram teores de $\mathrm{K}$ de 1,18 e $1,10 \mathrm{mg} / 100 \mathrm{~g}$, respectivamente, e na cultivar Rudá, esse teor foi de $1,07 \mathrm{mg} / 100 \mathrm{~g}$, diferindo apenas da cultivar Aporé (Tabela 2).

O comportamento das cultivares com relação ao teor de Ca foi diferenciado (Tabela 2), mostrando que os maiores teores foram obtidos com as cultivares Pérola e Rudá. A cultivar Aporé apresentou menor teor de Ca, diferindo significativamente da cultivar Pérola. Não houve influência da adubação nos teores de Ca, provavelmente devido aos altos teores no solo. Pela mesma razão, o teor de Mg nos grãos de feijão também não foi significativamente afetado pelas diferentes adubações, não havendo diferença entre as cultivares (Tabela 2). Altas concentrações de $\mathrm{Ca}$ e $\mathrm{Mg}$ nas paredes celulares contribuem no processo de endurecimento dos grãos, devido à formação de fitatos insolúveis de Ca e Mg, aumentando o tempo de cocção (CHIARADIA e GOMES, 1997).

Verifica-se, ainda, na Tabela 2, que o maior teor de $\mathrm{S}$ foi observado nas cultivares Rudá e Pérola, embora a cultivar Aporé não tenha diferido significativamente da Pérola. Identificar cultivares com maior teor de S é importante, pois o S é um nutriente absorvido em quantidades moderadas pela cultura do feijoeiro e é constituinte de aminoácidos e cistina, que são considerados limitantes na maioria dos alimentos (JORDAN e ENSMINGER, 1958).

Na Tabela 3, pode-se observar que não houve diferença significativa no teor de Zn com relação à adubação e à cultivar. A média do teor de Zn obtida com as três cultivares estudadas e nas diferentes adubações foi de $4,54 \mathrm{mg} / 100 \mathrm{~g}$.

Com relação ao teor de Fe (Tabela 3), o maior valor encontrado foi com a cultivar Rudá, que diferiu significativamente das cultivares Aporé e Pérola. Nas adubações $\mathrm{N}_{2}$ e $\mathrm{N}_{3}$, obtiveram-se os maiores teores de $\mathrm{Fe}$, que foram de 6,72 e $6,56 \mathrm{mg} / 100 \mathrm{~g}$, respectivamente. $\mathrm{Na}$ ausência da adubação, o teor de Fe foi de 6,44 mg/100g.

Os maiores teores de $\mathrm{Cu}$ foram encontrados nas cultivares Rudá e Aporé; no entanto, essa última não diferiu da cultivar Pérola quanto a esse nutriente. Considerando a média das cultivares, o maior teor de $\mathrm{Cu}$ foi obtido com a adubação $N_{3}$, ao passo que entre os tratamentos $\mathrm{N}_{1}$ e $\mathrm{N}_{2}$ não houve diferença significativa.

Verifica-se, também, na Tabela 3 que a adubação influenciou de maneira semelhante os teores de Mn e B, sendo os menores teores desses nutrientes encontrados no tratamento sem adubação $\left(\mathrm{N}_{1}\right)$. Esse tratamento diferiu apenas do tratamento $\mathrm{N}_{3}$, que proporcionou os maiores valores. Quanto ao Mn, os maiores valores encontrados foram de 5,55 mg/100 g e, quanto ao B, 21,03 mg/100 g. A cultivar Rudá superou as demais quanto ao teor de $\mathrm{Mn}$, e com relação ao teor de B, essa cultivar e a Aporé superaram a cultivar Pérola.

Com relação à qualidade nutricional, é importante conhecer os teores de micronutrientes contidos no grão de feijão, pois o Zn, Fe, Cu e Mn são considerados essenciais à dieta humana e dos animais, devido às relevantes funções desempenhadas no organismo e à possibilidade de sua ocorrência em níveis deficientes, excessivos ou desequilibrados na dieta.

Em geral, os teores de nutrientes encontrados nos grãos das diferentes cultivares mostraram pouca diferença. Segundo Thung e Oliveira (1998), isso ocorre quando a amostragem para análise é realizada em cultivares da mesma raça mesoamericana de feijoeiro, como é o caso das cultivares estudadas. Além disso, esses autores afirmam que as plantas e as sementes de feijoeiro obtidas com diferentes práticas culturais diferem no teor de nutrientes. 
TABELA 2 - Teores de Ca, Mg, S, P, K e N nos grãos das cultivares de feijão Aporé, Pérola e Rudá, em função de níveis de adubação $\left(\mathrm{N}_{1}, \mathrm{~N}_{2}, \mathrm{~N}_{3}\right)$. UEM, Maringá-PR, 2001.

\begin{tabular}{|c|c|c|c|c|}
\hline \multirow{2}{*}{ Adubação } & \multicolumn{4}{|c|}{ Cultivares } \\
\hline & Pérola & Rudá & Aporé & Média \\
\hline & \multicolumn{4}{|c|}{ Cálcio (mg/100g) } \\
\hline N1 & 0,63 & 0,62 & 0,56 & $0,60 \mathrm{a}$ \\
\hline N2 & 0,64 & 0,64 & 0,60 & $0,63 \mathrm{a}$ \\
\hline N3 & 0,66 & 0,64 & 0,62 & $0,64 \mathrm{a}$ \\
\hline \multirow[t]{2}{*}{ Média } & $0,64 \mathrm{~A}$ & $0,63 \mathrm{AB}$ & $0,59 \mathrm{~B}$ & \\
\hline & \multicolumn{4}{|c|}{ Magnésio (mg/100g) } \\
\hline N1 & 0,86 & 0,87 & 0,89 & $0,87 \mathrm{a}$ \\
\hline N2 & 0,86 & 0,88 & 0,91 & $0,88 \mathrm{a}$ \\
\hline N3 & 0,82 & 0,90 & 0,71 & $0,81 \mathrm{a}$ \\
\hline \multirow[t]{2}{*}{ Média } & 0,85 & 0,88 & 0,83 & \\
\hline & \multicolumn{4}{|c|}{ Enxofre (mg/100g) } \\
\hline N1 & 2,12 & 2,17 & 1,97 & $2,09 \mathrm{a}$ \\
\hline N2 & 2,13 & 2,20 & 2,05 & $2,13 \mathrm{a}$ \\
\hline N3 & 2,19 & 2,29 & 2,11 & $2,20 \mathrm{a}$ \\
\hline \multirow[t]{2}{*}{ Média } & $2,15 \mathrm{AB}$ & $2,22 \mathrm{~A}$ & $2,04 \mathrm{~B}$ & \\
\hline & \multicolumn{4}{|c|}{ Fósforo (mg/100g) } \\
\hline N1 & 0,35 & 0,28 & 0,34 & $0,35 \mathrm{a}$ \\
\hline N2 & 0,36 & 0,28 & 0,35 & $0,36 \mathrm{a}$ \\
\hline N3 & 0,31 & 0,31 & 0,37 & $0,31 \mathrm{a}$ \\
\hline \multirow[t]{2}{*}{ Média } & $0,37 \mathrm{~A}$ & $0,29 \mathrm{~B}$ & $0,36 \mathrm{~A}$ & \\
\hline & \multicolumn{4}{|c|}{ Potássio (mg/100g) } \\
\hline N1 & 1,03 & 1,02 & 1,14 & $1,03 \mathrm{a}$ \\
\hline N2 & 1,10 & 1,04 & 1,19 & $1,10 \mathrm{a}$ \\
\hline N3 & 1,19 & 1,14 & 1,21 & $1,19 \mathrm{a}$ \\
\hline \multirow[t]{2}{*}{ Média } & $1,10 \mathrm{AB}$ & $1,07 \mathrm{~B}$ & $1,18 \mathrm{~A}$ & \\
\hline & \multicolumn{4}{|c|}{ Nitrogênio (\%) } \\
\hline N1 & 3,62 & 3,35 & 3,69 & $3,55 \mathrm{c}$ \\
\hline N2 & 3,97 & 3,76 & 4,11 & $3,95 \mathrm{~b}$ \\
\hline N3 & 4,30 & 4,16 & 4,47 & $4,31 \mathrm{a}$ \\
\hline Média & $3,96 \mathrm{AB}$ & $3,75 \mathrm{~B}$ & $4,0 \mathrm{~s}$ & \\
\hline
\end{tabular}

Letras maiúsculas iguais na linha e letras minúsculas iguais na coluna indicam que as médias não diferem entre si, pelo teste Duncan $(\mathrm{P}>0,05)$.

$\mathrm{N}_{1}=$ Sem adubação; $\mathrm{N}_{2}=20-30-20 \mathrm{~kg}^{-1} \mathrm{a}^{-1} \mathrm{Ne}, \mathrm{P}_{2} \mathrm{O}_{5}$ e $\mathrm{K}_{2} \mathrm{O}$ respectivamente no plantio, mais $20 \mathrm{~kg}$ de $\mathrm{N}$ ha $^{-1}$ em cobertura; e $N_{3}=40-70-20 \mathrm{~kg} \mathrm{ha}^{-1}$ de $N, P_{2} \mathrm{O}_{5}$ e $\mathrm{K}_{2} \mathrm{O}$ no plantio, mais $60 \mathrm{~kg}$ de $\mathrm{N} \mathrm{ha}^{-1}$ em cobertura. 
TABELA 3 - Teores de micronutrientes nos grãos das cultivares de feijão Aporé, Pérola e Rudá, em função de níveis de adubação $\left(\mathrm{N}_{1}, \mathrm{~N}_{2}, \mathrm{~N}_{3}\right)$. UEM, Maringá-PR, 2001.

\begin{tabular}{|c|c|c|c|c|}
\hline \multirow{2}{*}{ Adubação } & Pérola & Rudá & Aporé & Média \\
\hline & \multicolumn{4}{|c|}{ Zinco (mg/100g) } \\
\hline N1 & 4,34 & 4,58 & 4,44 & $4,45 \mathrm{a}$ \\
\hline N2 & 4,40 & 4,56 & 4,45 & 4,47 a \\
\hline N3 & 4,83 & 4,74 & 4,60 & $4,72 \mathrm{a}$ \\
\hline \multirow[t]{2}{*}{ Média } & 4,52 & 4,63 & 4,49 & \\
\hline & \multicolumn{4}{|c|}{ Cobre (mg/100g) } \\
\hline N1 & 1,57 & 1,71 & 1,63 & $1,63 \mathrm{~b}$ \\
\hline N2 & 1,61 & 1,74 & 1,73 & $1,69 \mathrm{~b}$ \\
\hline N3 & 1,73 & 1,80 & 1,78 & 1,77 a \\
\hline \multirow[t]{2}{*}{ Média } & $1,63 \mathrm{~B}$ & $1,75 \mathrm{~A}$ & $1,71 \mathrm{AB}$ & \\
\hline & \multicolumn{4}{|c|}{ Boro (mg/100g) } \\
\hline N1 & 18,49 & 20,76 & 19,83 & $19,69 \mathrm{~b}$ \\
\hline N2 & 18,87 & 21,21 & 20,33 & $20,14 \mathrm{ab}$ \\
\hline N3 & 19,25 & 22,26 & 21,57 & 21,03 a \\
\hline \multirow[t]{2}{*}{ Média } & $18,87 \mathrm{~B}$ & $21,41 \mathrm{~A}$ & $20,58 \mathrm{~A}$ & \\
\hline & \multicolumn{4}{|c|}{ Ferro (mg/100g) } \\
\hline N1 & 6,21 & 6,72 & 6,40 & $6,44 \mathrm{~b}$ \\
\hline N2 & 6,26 & 6,91 & 6,51 & $6,56 a b$ \\
\hline N3 & 6,43 & 7,19 & 6,55 & $6,72 \mathrm{a}$ \\
\hline \multirow[t]{2}{*}{ Média } & $6,30 \mathrm{~B}$ & $6,94 \mathrm{~A}$ & $6,49 \mathrm{~B}$ & \\
\hline & \multicolumn{4}{|c|}{ Manganês (mg/100g) } \\
\hline N1 & 2,83 & 5,99 & 4,06 & $4,30 \mathrm{~b}$ \\
\hline N2 & 3,41 & 6,99 & 4,83 & $5,07 \mathrm{ab}$ \\
\hline N3 & 4,24 & 7,32 & 5,08 & 5,55 a \\
\hline Média & $3,49 \mathrm{C}$ & $6,77 \mathrm{~A}$ & 4,66 B & \\
\hline
\end{tabular}

Letras maiúsculas iguais na linha e letras minúsculas iguais na coluna indicam que as médias não diferem entre si, pelo teste Duncan $(\mathbf{P}>\mathbf{0 , 0 5})$.

$\mathrm{N}_{1}=$ Sem adubação; $\mathrm{N}_{2}=20-30-20 \mathrm{~kg} \mathrm{ha}^{-1}$ de $\mathrm{N}, \mathrm{P}_{2} \mathrm{O}_{5}$ e $\mathrm{K}_{2} \mathrm{O}$, respectivamente no plantio, mais $20 \mathrm{~kg}$ de $\mathrm{N}$ ha 1 em cobertura; e $N_{3}=40-70-20 \mathrm{~kg} \mathrm{ha}^{-1}$ de $N, P_{2} O_{5}$ e $K_{2} O$ no plantio, 60 kg de $N$ ha-1em cobertura. 
ANDRADE, C. A. de B. et al.

TABELA 4 - Teores de triptofano e proteína nos grãos das cultivares de feijão Aporé, Pérola e Rudá, em função de níveis de adubação $\left(\mathrm{N}_{1}, \mathrm{~N}_{2}, \mathrm{~N}_{3}\right)$. UEM, Maringá-PR, 2001

\begin{tabular}{ccccc}
\hline Adubação & Pérola & Rudá & Aporé & Média \\
\hline & & \multicolumn{2}{c}{ Proteína (\%) } \\
\cline { 2 - 5 } N1 & 22,61 & 20,95 & 23,07 & $22,21 \mathrm{c}$ \\
N2 & 24,82 & 23,47 & 25,72 & $24,67 \mathrm{~b}$ \\
N3 & 26,89 & 25,96 & 27,95 & 26,94 a \\
\hline Média & $24,77 \mathrm{AB}$ & $23,47 \mathrm{~B}$ & $25,58 \mathrm{~A}$ \\
\hline & & Triptofano (mg/100g) & $0,56 \mathrm{c}$ \\
N1 & 0,57 & 0,52 & 0,60 & $0,67 \mathrm{~b}$ \\
N2 & 0,68 & 0,61 & 0,73 & $0,75 \mathrm{a}$ \\
\hline N3 & 0,76 & 0,69 & 0,81 & \\
\hline
\end{tabular}

Letras maiúsculas iguais na linha e letras minúsculas iguais na coluna indicam que as médias não diferem entre si, pelo teste Duncan $(\mathrm{P}>0,05)$.

$\mathrm{N}_{1}=$ Sem adubação; $\mathrm{N}_{2}=20-30-20 \mathrm{~kg} \mathrm{ha}^{-1}$ de $\mathrm{N}, \mathrm{P}_{2} \mathrm{O}_{5}$ e $\mathrm{K}_{2} \mathrm{O}$ respectivamente no plantio, mais $20 \mathrm{~kg}$ de $\mathrm{N}$ ha ${ }^{1}$ em cobertura; e $\mathrm{N}_{3}=40-70-20 \mathrm{~kg} \mathrm{ha}^{-1}$ de $\mathrm{N}, \mathrm{P}_{2} \mathrm{O}_{5}$ e $\mathrm{K}_{2} \mathrm{O}$ no plantio, mais $60 \mathrm{~kg}$ de $\mathrm{N}$ ha-1 em cobertura.

O teor de proteína e triptofano diferiu com as adubações e entre as cultivares estudadas (Tabela 4). O maior teor de proteína nos grãos foi obtido com a adubação $\mathrm{N}_{3}$, seguido pelas adubações, $\mathrm{N}_{2}$ e $\mathrm{N}_{1}$. As cultivares Aporé e Pérola apresentaram teores mais elevados de proteína. Esses resultados estão de acordo com Edje et al. (1975) que, estudando em condição de campo o efeito de diversos teores de nitrogênio $\left(0 ; 40 ; 80 ; 120 ; 160\right.$ e 200 kg de N.ha $\left.{ }^{-1}\right)$, observaram que a porcentagem de proteína nos grãos estava intimamente correlacionada com o nível de nitrogênio aplicado.

Com relação ao teor de triptofano, verifica-se, na Tabela 4, que os maiores teores foram em ordem decrescente de $0,75,0,67$ e $0,58 \mathrm{mg} / 100 \mathrm{~g}$, respectivamente, para as adubações $\mathrm{N}_{3}, \mathrm{~N}_{2}$ e sem adubação $\left(\mathrm{N}_{1}\right)$. Já, para as cultivares, os teores de triptofano foram de $0,71,0,67$ e $0,60 \mathrm{mg} / 100 \mathrm{~g}$, respectivamente, para Aporé, Pérola e Rudá.

Com a adubação $\mathrm{N}_{3}$, a cultivar Aporé apresentou maior quantidade de $\mathrm{N}$ e, conseqüentemente, de proteína e triptofano (pois o $\mathrm{N}$ faz parte de sua composição), seguida pelas cultivares Pérola e Rudá.
Tandom et al. (1957), citados por Sgarbieri e Whitaker (1982), mostraram baixas concentrações de metionina e triptofano em 25 variedades de feijão da América Central. A metionina variou entre 0,80 e 1,39\% (aminoácido/100g de proteína), o triptofano entre 0,56 e $0,94 \%$ e a lisina entre 7,22 e $9,22 \%$. A concentração de proteína total encontrada variou de 20,1 a $27,9 \%$.

\section{CONCLUSÕES}

a) As adubações utilizadas no presente trabalho foram suficientes para alcançar os níveis de produtividades esperados.

b) A recomendação de adubação para atingir produtividade superior a $2.500 \mathrm{~kg} \mathrm{ha}^{-1}$ de grãos proporcionou os maiores teores de $\mathrm{K}, \mathrm{N}, \mathrm{Fe}, \mathrm{Cu}, \mathrm{Mn}, \mathrm{B}$, proteína e triptofano nos grãos de feijão.

c) Pelos resultados encontrados, verifica-se a necessidade de se efetuar a adubação nesse tipo de solo, independentemente da cultivar, para se obter alta produtividade e altos teores de nutrientes, proteína e triptofano nos grãos de feijão. 


\section{REFERÊNCIAS BIBLIOGRÁFICAS}

ANDRADE, C. A. B. Limitações de fertilidade e efeito do calcário para o feijoeiro (Phaseolus vulgaris L.) em solos de várzea do sul de Minas Gerais. 1997. 107 f. Tese (Doutorado em Fitotecnia) - Universidade Federal de Lavras, Lavras, 1997.

ARAÚJO, R. S. Cultura do feijoeiro comum no Brasil. Piracicaba: Potafos, 1996. 786 p.

ARF, O. Efeitos na cultura do trigo da rotação com milho e adubos verdes, na presença e na ausência de adubação nitrogenada. Bragantia, Campinas, v. 58, n. 2, p. 323-334, 1999.

ASSOCIATION OF OFFICIAL ANALYTICAL CHEMISTS. Official methods of analysis. 12. ed. Washington, 1975. $1094 \mathrm{p}$.

BARAMPAMA, Z.; SIMARD, R. E. Nutrient composition, protein quality and antinutritional factors of some varieties of dry beans (Phaseolus vulgaris L.) grown in Burundi. Food Chemistry, Easton, v. 47, p. 159-67, 1993.

CAMPOS, H. Estatística aplicada à experimentação com cana-de-açúcar. Piracicaba: FEALQ, 1984. $292 \mathrm{p}$.

CHIARADIA, A. C. N.; GOMES, J. C. Feijão: química, nutrição e tecnologia. Viçosa: Fundação Arthur Bernardes, 1997. 180 p.

CLEMENTE, E.; PORTELA, B. F. Effect of sodium lauryl sulfate in solubilizing protein for tryptophan determination. Journal of Food Biochemistry, Connecticut, v. 12, n. 1, p. 61-68, Aug. 1987.

COMISSÃO DE FERTILIDADE DO SOLO DO ESTADO DE MINAS GERAIS. Recomendações para o uso de corretivos e fertilizantes em Minas Gerais: $5^{\text {a }}$ aproximação. Viçosa, 1999. 359 p.

CONAB. Previsão e acompanhamento da safra 2002/2003: quarto levantamento, abril/2003. Disponível em: <http://www.conab.gov.br>. Acesso em: 22 nov. 2003.

EDJE, O. T.; MUGHOGHO, L. K.; AYONOADU, U. W. U. Responses of dry beans to verying nitrogen levels. Agronomy Journal, Madison, v. 6, n. 2, p. 251255, 1975.
EMPRESA BRASILEIRA DE AGROPECUÁRIA. Centro Nacional de Pesquisa de Solos. Sistema brasileiro de classificação de solos. Brasília; Rio de Janeiro, 1999. $412 \mathrm{p}$.

FERNANDES, L. A. Fósforo e atividade da fosfatase ácida em plantas de feijoeiro. Pesquisa Agropecuária Brasileira, Brasília, v. 33, n. 5, p. 373-384, 1998.

FERNANDES, M. I. P. S. Efeito da variação de estande dos experimentos com a cultura do feijoeiro. 1987. 73 f. Dissertação (Mestrado em Agronomia) Universidade Federal de Lavras, Lavras, 1987.

GUERRA, A. F.; SILVA, D. B.; RODRIGUES, G. C. Manejo de irrigação e fertilização nitrogenada para o feijoeiro na região dos cerrados. Pesquisa Agropecuária Brasileira, Brasília, v. 35, n. 6, p. 1229-1236, 2000.

JONHSON, C. M.; URICH, A. Analytical methods for use in plant analyses. Los Angeles: University of California, 1959. 247 p.

JORDAN, H. V.; ENSMINGER, L. E. The role of sulfur in soil fertility. Advances Agronomy, New York, v. 10, p. 407-434, 1958.

MALAVOLTA, E. Manual de química agrícola: adubos e adubação. São Paulo: Agronômica Ceres, 1981. 596 p.

MALAVOLTA, E.; VITTI, G. C.; OLIVEIRA, S. A. Avaliação do estado nutricional das plantas: princípios e aplicações. 2. ed. Piracicaba: POTAFOS, 1997. 319 p.

OPIENSKA-BLOUTH, J.; CHAREZINSK, M.; BERBEC, $\mathrm{H}$. A new rapid method of determining tryptophan. Analytical Biochemistry, New York, v. 6, n. 1, p. 69-76, July 1963.

ROSOLEM, C. A.; MARUBAYASHI, O. M. Seja o doutor do seu feijoeiro. Arquivo do Agrônomo, [S.l.], n. 7, p. 1-16, 1994. Encarte Informações Agronômicas.

SGARBIERI, V. C.; WHITAKER, J. R. Physical, chemical and nutritional properties of common bean (Phaseolus) proteins. Advances in Food Research, [S.l.], v. 28, p. 93-166, 1982.

TEIXEIRA, I. R. Resposta do feijoeiro (Phaseolus vulgaris L. cv. Pérola) a diferentes densidades de semeadura e doses de nitrogênio. Ciência e Agrotecnologia, Lavras, v. 24, n. 2, p. 399-408, abr./jun. 2000. 
THUNG, M. D. T.; OLIVEIRA, I. P. de. Problemas abióticos que afetam a produção do feijoeiro e seus métodos de controle. Santo Antônio de Goiás: EMBRAPA-CNPAF, 1998. 172 p.
VIEIRA, C.; BORÉM, A.; RAMALHO, M. A. P. Melhoramento do feijão. In: BORÉM, A. Melhoramento de espécies cultivadas. Viçosa: UFV, 1999. p. 273-349.

Ciênc. agrotec., Lavras, v. 28, n. 5, p. 1077-1086, set.out., 2004 